\title{
Des- $\gamma$-Carboxy Prothrombin (DCP) as a Potential Autologous Growth Factor for the Development of Hepatocellular Carcinoma
}

\author{
Yu-Sheng Zhang ${ }^{a} \quad$ Jia-Hui Chu ${ }^{a}$ Shu-Xiang Cuib Zhi-Yu Song ${ }^{a} \quad$ Xian-Jun Qu \\ aSchool of Pharmaceutical Sciences, Shandong University, Jinan; 'bvaluation Center for Food and Drug, \\ Capital Medical University, Beijing, China
}

\section{Key Words}

Des- $\gamma$-carboxy prothrombin (DCP) $\bullet$ Hepatocellular carcinoma $(\mathrm{HCC}) \cdot$ Autologous growth factor $\bullet$ Paracrine factor $\bullet$ Stimulation $\bullet$ Angiogenesis $\bullet$ Signaling pathways

\begin{abstract}
Des- $\gamma$-carboxy prothrombin (DCP) is a prothrombin precursor produced in hepatocellular carcinoma (HCC). Because of deficiency of vitamin $\mathrm{K}$ or $\mathrm{\gamma}$-glutamyl carboxylase in HCC cells, the 10 glutamic acid (Glu) residues in prothrombin precursor did not completely carboxylate to $\gamma$-carboxylated glutamic acid (Gla) residues, leaving some Glu residues remained in $\mathrm{N}$-terminal domain. These prothrombin precursors with Glu residues are called DCPs. DCP displays insufficient coagulation activity. Since Liebman reported an elevated plasma DCP in patients with HCC, DCP has been used in the diagnosis of HCC. Recently, its biological malignant potential has been specified to describe DCP as an autologous growth factor to stimulate HCC growth and a paracrine factor to integrate HCC with vascular endothelial cells. DCP was found to stimulate HCC growth through activation of the DCP-Met-JAK1-STAT3 signaling pathway. DCP might increase HCC invasion and metastasis through activation of matrix metalloproteinase (MMPs) and the ERK1/2 MAPK signaling pathway. DCP has also been found to play a crucial role in the formation of angiogenesis. DCP could increase the angiogenic factors released from HCC and vascular endothelial cells. These effects of DCP in angiogenesis might be related to activation of the DCP-KDR-PLC- $\gamma$-MAPK signaling pathway. In this article, we summarized recent studies on DCP in biological roles related to cancer progression and angiogenesis in HCC.
\end{abstract}


Zhang et al.: DCP is a Potential Autologous Growth Factor for HCC

\section{Introduction}

Des- $\gamma$-carboxy prothrombin (DCP) is a prothrombin precursor produced in hepatocellular carcinoma (HCC). DCP lacks the activity of interacting with other coagulation factors $[1,2]$. Since Liebman et al. reported an elevated plasma DCP in patients with HCC, DCP has been considered as a specific marker for diagnosis of HCC [3-6]. Elevated serum DCP levels have been found in 44-81\% of HCC patients [4]. High level of DCP has been considered to be associated with large tumor and recurrence of HCC. Recent studies have shown that DCP might play important roles in the development of HCC. A significant association between an elevated DCP level and worse tumor behavior has been established [7]. From these studies, we suggest that, after secretion from HCC, DCP might work as an autologous growth factor for HCC growth and as a paracrine interaction factor between HCC and vascular endothelial cells to further stimulate HCC progression [8]. In this paper, we summarized recent studies on the characteristics of DCP, the significance as a diagnostic marker and its biological roles related to cancer progression and angiogenesis in HCC.

\section{The structure of DCP}

DCP is the prothrombin precursor maintaining some glutamic acid (Glu) residues in the N-terminal domain [9]. In hepatocyte, prothrombin is synthesized depending on the presence of vitamin K-dependent $\gamma$-glutamyl carboxylase [10, 11]. As shown in Fig. 1, in human prothrombin structure, there are ten $\gamma$-carboxylated glutamic acid (Gla) residues in the N-terminal domain, which are called Gla domain. These Gla residues are originally glutamic acid (Glu) residues in prothrombin precursor. The ten Glu residues are respectively at the positions of $6,7,14,16,19,20,25,26,29$, and 32 in N-terminal domain $[1,12]$. In hepatocyte, these Glu residues must be converted into Gla residues before prothrombin obtains the coagulation activity. This conversion is the process of post-translational modification of prothrombin in the lumen of endoplasmic reticulum [13]. However, in HCC cells, there may occur vitamin K deficiency or vitamin K antagonists, leading to lower activity of $\gamma$-glutamyl carboxylase $[14,15]$. HCC cells are therefore unable to completely carboxylate these Glu residues into Gla, resulting some Glu residues leaving in N-terminal domain. These proteins are called prothrombin precursors or des- $\gamma$-carboxy prothrombin (DCP). Moreover, these 10 Glu residues did not completely carboxylate to Gla. Thus, DCP might contain various variants (DCPs) [16]. The occurrence of these DCP variants seems to be characteristic and, consequently, we hypothesize that the progression of des- $\gamma$-carboxylation in HCC cells is not accomplished by single steps, and that it rather advances rapidly through two to three stages instead.

Currently, an important issue is that how many Glu residues are present in DCP protein. By using immunoaffinity chromatography, Liska et al. indicated that it is unlikely that the enzyme acts to randomly carboxylate the 10 potential Gla sites [17]. It is assumed that the 10 -Gla residues might be $\gamma$-carboxylation from $\mathrm{N}$-terminal domain following the sequence of residues 26, 25, 16, 29, 20, 19, 14, 32, 7 and 6 (Fig. 1). This process of $\gamma$-carboxylation proceeds three-dimensionally from the inside to the outside of the Gla-domain, with S-S binding then occurring at the positions of 17 and 22 from the N-terminal $[12,18]$. It is apparent that there is a wide difference in the degree of carboxylation between different Glu residues and when carboxylation is more or less complete. The more amino-terminals of those residues are, the more the carboxylation is complete $[12,17]$. According to the number of Gla and their positions, DCPs have various variants and the number of Gla is related to their biological activity [19]. Using the technology of the reverse-phase high performance liquid chromatography (HPLC), Uehara et al. separated different DCP variants during the processes of prothrombin biosynthesis [20]. They then established a relationship between the number of the carboxylated Glu residues and their biochemical functions in these DCP variants. The results revealed that the progression of HCC is not only related to high level of 


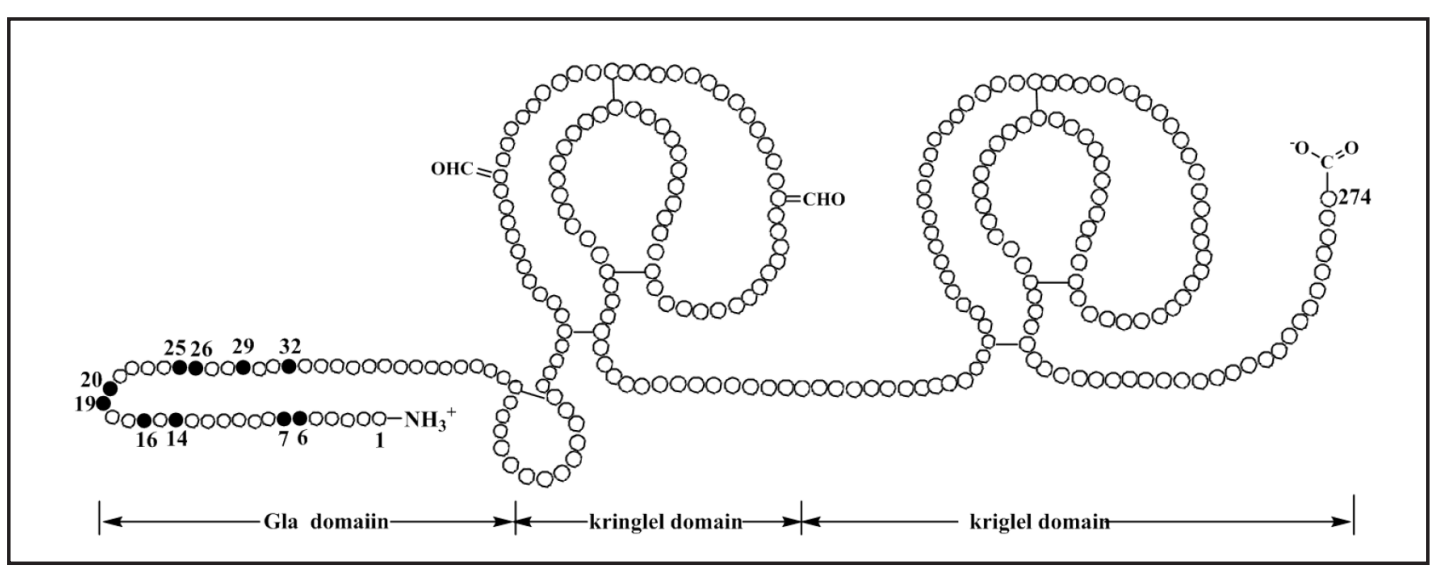

Fig. 1. Diagram representing the order of carboxylation of Gla domain in prothrombin. In hepatocyte, the 10 Glu residues must be converted into Gla residues before prothrombin obtains coagulation activity. These Gla residues were carboxylated in order from $\mathrm{N}$-terminal (residues 26, 25, 16, 29, 20, 19, 14, 32,7 and 6). If less than 10 Glu residues convert to Gla residues, the protein is called DCP.

plasma DCP, but also with the number of DCP variants. For example, HCC patients with high content of Glu residues might have contracted more progressed disease [20, 21]. Liebman et al. found that the hepatoma-associated DCP contained an average of four to five or more Glu residues per molecule as compared to less than four Glu residues per molecule of DCP separated from the benign liver diseases. Further studies indicated that these DCP variants might have different biochemical functions in the progression of HCC [16]. However, these functions behind different DCP variants are still far from being defined.

It is well known that normal prothrombin exerts its activity of coagulation through binding with calcium [22]. This binding is mostly dependent on the structural integrity of prothrombin. Further analysis indicated that Gla residues at the positions of 16, 26 and 29, through their interactions with calcium ions, which might be essential for the preservation of the structural integrity of the domain [18-20]. Because DCP might contain Glu residues at the positions of 16,26 and 29, it is therefore unable to perverse the conformation necessary binding to the phospholipid surface where prothrombin activation occurs even if calcium ions are present $[18,20]$. As number of Gla residues decreases, the coagulant activity is thought to be gradually lost, in particular, with less than 3 Gla residues of DCPs $[18,20]$.

\section{The causes and mechanisms of DCP production}

The causes and mechanisms of DCP production are poorly understood. Some studies revealed that DCP is not only found in the HCC tissues, but also in the non-cancer tissues surrounding HCC and even in some benign liver diseases, such as acute hepatitis and chronic hepatitis $[20,23,24]$. These observations imply the complicated causes and mechanisms of DCP production. The following analysis of recent studies might provide some clues for understanding the mechanisms of DCP synthesis in HCC tissues. Firstly, hypoxia in the HCC tissues might result in the increase of synthesis of DCP $[25,26]$. It is well known that hypoxia often occurs in the HCC tissues [27]. Hypoxia could induce epithelial-mesenchymal transition (EMT). In the HCC tissues, hypoxic stimulation might disrupt fine filamentous actin network, which has a crucial role for clathrin-mediated endocytosis of vitamin K. Therefore hypoxia stimulation followed by EMT might cause the impairment uptake of vitamin K and then induce DCP production [27, 28]. Further studies suggested that DCP production was associated with high expression of hypoxia-inducible factor (HIF)-1 $\alpha$ in the HCC tissues and the non-cancer tissues surrounding HCC tissues [20]. Suzuki et al. found that both severe hypoxia with nutrient deprivation and HIF-1 $\alpha$ transfection could lead to high level of DCP [26]. Secondly, the phenotypic changes of HCC cells might cause DCP production [26]. 
Several studies showed that the cytoskeletal rearrangement in HCC cells might be associated with the cause of DCP production $[29,30]$. During the phenotypic conversion of HCC cells, the action of cytoskeletal rearrangement might lead to the impairment of vitamin $\mathrm{K}$ uptake. High level of DCP was thus always detected in these HCC cells [31]. Whatever the causes, the following suggestions have been widely accepted as possible mechanisms of DCP production.

\section{Decrease of $\gamma$-glutamyl carboxylase in HCC cells}

It is well known that vitamin K-dependent $\gamma$-glutamyl carboxylase plays a key role in converting prothrombin precursor into prothrombin with vitamin $\mathrm{K}$ epoxide reductase (VKOR) as cofactor [32]. This conversion is the process of posttranslational modification in the lumen of endoplasmic reticulum in normal hepatocyte. However, in HCC cells, $\gamma$-glutamyl carboxylase might be deficient, resulting in deficiency of converting prothrombin precursor into prothrombin (Fig. 2). In clinic studies, Yamagata et al. examined the contents of $\gamma$-glutamyl carboxylase and DCP in the HCC tissues. The results revealed that the activity of $\gamma$-glutamyl carboxylase per unit amount of endogenous microsomal prothrombin precursor markedly decreased in the HCC tissues as compared with the non-HCC liver tissues [33]. In animal experiment, Shah et al. examined the levels of $\gamma$-glutamyl carboxylase in the Morris hepatoma tumor bearing in rat models. The result showed that the DCP-positive HCC tissues contained lower level of $\gamma$-glutamyl carboxylase than that of the DCP-negative HCC tissues [34]. Similar results were observed in many other experiments in the DCP-producing and non-DCP-producing hepatoma cell lines [35]. In addition, a recent study showed an over expression of a splice variant of $\gamma$-glutamyl carboxylase in the DCP-producing HCC cell lines [36]. However, the roles of this splice variant of $\gamma$-glutamyl carboxylase have not been understood during the synthesis of DCP in HCC.

\section{Vitamin K deficiency in vitamin K cycle in HCC tissues}

Vitamin $\mathrm{K}$ is a fat-soluble essential vitamin. The only known of its role is as a co-factor for $\gamma$-glutamyl carboxylase [37]. During the $\gamma$-carboxylation of Glu residues in lumen of endoplasmic reticulum, vitamin $\mathrm{K}$ is converted from active form to vitamin $\mathrm{K}$ 2,3-epoxide, which must be recycled to the active form by vitamin K epoxide reductase (VKOR) to maintain coagulation cycle [38]. However, vitamin K was found at a lower level in HCC tissues as compared with normal liver tissues [39]. A clear correlation between vitamin K deficiency and DCP production existed in the HCC tissues [40,41]. Moreover, administration of warfarin, the vitamin K antagonist, could also stimulate DCP production in the HCC tissues [42]. We therefore suggested that vitamin $\mathrm{K}$ deficiency or vitamin $\mathrm{K}$ antagonist might antagonize VKOR or prevent vitamin K recycling, leading to decrease of $\gamma$-glutamyl carboxylase (Fig. 2). This hypothesis was supported by many data in our group and other clinical observations. In our group's study, HCC cell lines PLC/PRF/5 and HepG2 were exposed to vitamin $\mathrm{K}_{2}$ for different times. The level of DCP in supernatant of cell culture was determined by an electrochemiluminescence immunoassay. The results showed that Vitamin $K_{2}(2-40 \mu \mathrm{M})$ significantly decreased DCP production [43]. Importantly, the effect of vitamin $\mathrm{K}_{2}$ on DCP production was observed in nude mice bearing HCC xenografts. As a result of vitamin $\mathrm{K}_{2}$ administration, the capacity of HCC xenografts was obviously inhibited [43]. In clinical studies, Ishizuka et al. evaluated the effects of menatetrenone, which is a vitamin $\mathrm{K}_{2}$ analog, on recurrence of hepatocellular carcinoma after surgical resection. Menatetrenone had a moderate inhibitory effect on HCC recurrence and DCP production. In contrast, high levels of plasma DCP were detected in HCC patients with no vitamin K administration [44]. Vitamin $\mathrm{K}_{1}$ might also possess the activity of decreasing DCP production. Injection of vitamin $\mathrm{K}_{1}$ strongly reduced the levels of plasma DCP, with $93 \%$ of patients showing tumor marker responses by decreased DCP levels [45].

\section{Overproduction of prothrombin in HCC tissues}

Some reports revealed that high level of DCP production was always related to overproduction of prothrombin in the HCC tissues. Ono et al. examined the ratio of prothrom- 


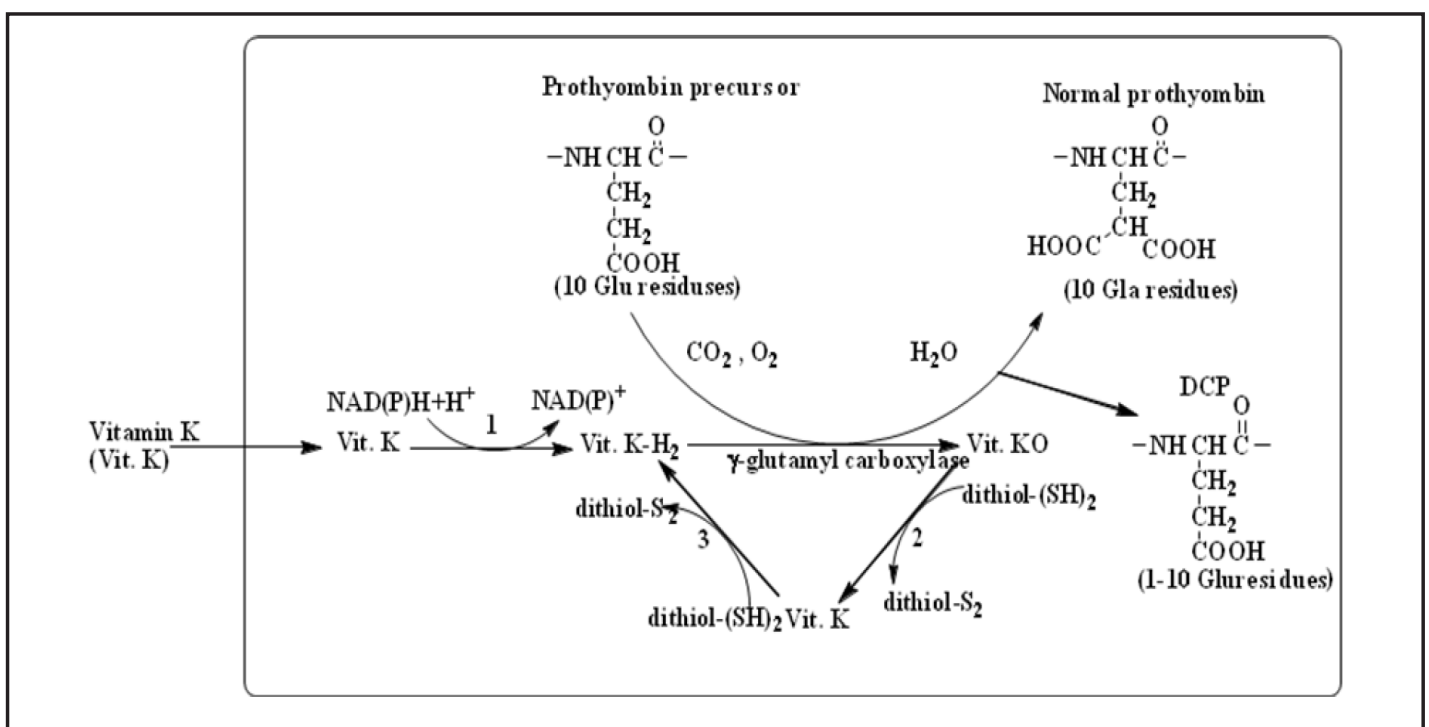

Fig. 2. The production of normal prothrombin and DCP in hepatic cells. In normal conditions, $\gamma$-glutamyl carboxylase completely converts the 10 Glu residues in Gla domain of prothrombin precursor to 10 Gla residues in the presence of vitamin $\mathrm{K}$ as a co-factor. In abnormal conditions, because of low activity of $\gamma$-glutamyl carboxylase or vitamin K deficiency, $\gamma$-carboxylation might be insufficient, leading to some Glu residues in Gla domain. If less than 10 Glu residues are converted to Gla residues, the protein is called DCP.

bin and DCP production in the HCC tissues by the immunoreactive staining assay. A correction between high levels of prothrombin and the elevated DCP was observed. Further study found lower level of $\gamma$-glutamyl carboxylase per unit amount of endogenous prothrombin precursor in the HCC tissues in comparison with the non-HCC liver tissues [46]. In HCC cell lines huH-1 and huH-2, which produced large amounts of DCP, high level of prothrombin was determined [47].

The possible mechanisms of DCP production in HCC are suggested in Fig. 2.

\section{The significance and marker for HCC diagnosis}

As one of three most common markers, DCP has been used for diagnosis of HCC. Other two plasma markers are alpha-fetoprotein (AFP) and Lens culinaris agglutinin-reactive fraction of AFP (AFP-L3) [4, 48]. Mountains of reports have been issued to describe the clinical significance of HCC markers [49]. In addition, these markers are also used for monitoring treatment responsiveness and tumor recurrence. High level of plasma DCP has been considered to be associated with large size of HCC. Tumor recurrence and metastasis are more frequent in patients with positive DCP than in patients with negative DCP. Plasma DCP level is usually determined by the enzyme immunoassay. For initial versions of the assay, the lower limit of detection is $0.0625 \mathrm{AU} / \mathrm{ml}(\mathrm{AU}$, arbitrary unit; $1 \mathrm{AU}$ is equivalent to $1 \mathrm{mg} / \mathrm{ml}$ of prothrombin). The cut-off level was set at $0.1 \mathrm{AU} / \mathrm{ml}(100 \mathrm{mAU} / \mathrm{ml})[4,50]$. By this assay, 44-81\% of HCC patients could be diagnosed. However, among these patients, only $15-30 \%$ with HCC $<3 \mathrm{~cm}$ in diameter was detected $[4,51]$. To improve its specificity and sensitivity, some revised enzyme immunoassays were developed. For example, by using $19 B 7$ or MU-3 antibodies both reacted to 1-, 3- and 4-Gla DCP, the 1-, 3- and 4-Gla variants by HCC cells, the cut-off serum DCP level is set at $40 \mathrm{mAU} / \mathrm{ml}[52,53]$. This revised cut-off level could improve the rate of early detection of HCC small less than $2 \mathrm{~cm}$ in diameter [53]. According to recent reports, this revised enzyme immunoassay has a sensitivity of $48-62 \%$ and specificity of $81-98 \%$ for determination of patients with HCC [4]. 
An important issue is that whether DCP is superior to AFP in diagnosis of HCC. AFP has been considered as an ideal marker for diagnosis of HCC from the 1960s [4]. AFP could also be used for monitoring the treatment efficacy and recurrence of HCC [54]. Previous studies indicated that combination of two or three HCC markers might greatly improve the sensitivity and diagnostic accuracy [55-57]. In fact, the mechanisms of DCP and AFP are mutually independent and therefore the differences in diagnosis of HCC exist between these two markers. Firstly, the levels of DCP and total AFP did not correlate either positively or negatively with each other in the same patients [58]. Secondly, as compared to AFP, DCP might be more specific as a marker for HCC because other liver diseases rarely give rise to DCP. But, the accuracy of DCP might be diminished in prolonged obstructive jaundice, intrahepatic cholestasis with vitamin $\mathrm{K}$ deficiency, and intake of warfarin and even some antibiotics [4]. Thirdly, DCP might be a better marker than AFP in detecting early stage of HCC with tumors smaller than $2 \mathrm{~cm}[4,59]$. Fourthly, the half-life of plasma DCP around 40-72 hours is much shorter than that of AFP around 5-7 days. DCP thus reflects treatment effect in a timelier manner [4, 60]. Finally, unlike AFP, plasma DCP level is considered to correlate to the stages of HCC as well as survival. High levels of DCP might be associated with higher rate of intrahepatic metastasis, portal vein tumor invasion and hepatic vein tumor thrombosis etc $[4,61]$.

\section{The stimulator of HCC growth and invasion}

As described above, high level of DCP was described to associates to larger tumor size, invasion and metastasis and even recurrence of HCC. However, the molecular basis for these observations has rarely been understood. Recently, malignant progression and metastasis of HCC has been shown (by us and others) to be associated with the activation of abnormal signaling pathways by DCP. In these studies, DCP was described as an important autologous growth factor to stimulate HCC growth and also a paracrine interaction factor between HCC cells and vascular endothelial cells to further increase angiogenesis.

\section{DCP activation c-Met phosphorylation might be the fundament for trigger various cellular events related to HCC progression}

Immunohistochemical analysis showed that high levels of c-Met, especially phosphorylated c-Met, were always associated with the DCP-positive HCC tissues [62]. Many clinical studies indicated that concurrently expressions of DCP and phosphorylated c-Met are mostly exhibited the progressed HCC [63]. In our study, we observed high levels of phosphorylated c-Met in the HCC cells following DCP stimulation. In HLE and SK-Hep which are the DCP-negative cell lines, DCP with 10-160 ng/ml for $24 \mathrm{~h}$ exposure significantly increased the expression of the phosphorylated c-Met by up to $106.2 \%$. Its downstream signals such as EGFR and MMPs were consequently activated [64]. In response to DCP stimulation, DNA synthesis was activated, and the proliferation and migration of HCC cells were consequently increased. In these activated downstream signals, the activation of the phosphorylated-EGFR is crucial for the progression of HCC. Activation of EGFR might provide basic drive for binding many ligands such as epidermal growth factor, TGF-a, amphiregulin b-cellulin, heparinbinding EGF-like growth factor, and epiregulin. Such binding could lead to activation of many other biochemical and physiological responses involving in mitogenic signal transduction in HCC cells. Further analysis indicated that c-Met is a high affinity tyrosine kinase receptor for hepatocyte growth factor (HGF). HGF has been identified as the ligand for c-Met [65]. Inagaki et al. showed that activation of c-Met phosphorylation in HepG2 cells induced by DCP was always correlated with the proliferation of HCC [62]. Suzuki et al. indicated that DCP might bind with c-Met at Tyr1234/1235 site [66]. This binding might be a critical step for activation of the kinase cascade in the following signaling pathways. Because of this binding, the phosphorylation of c-Met might interact with HGF and then lead to autophosphorylation of multiple tyrosines, which recruit several downstream signaling components, such as 
Zhang et al.: DCP is a Potential Autologous Growth Factor for HCC

JAK1-STAT3, MMPs, ERK1/2 MAPK, EGFR-Ras-Raf-MEK-ERK kinase cascade, KDR-PLC- $\gamma$ MAPK, Gab1, c-Cbl and PI3 kinase, ERK-MAPK, STAT, and PI3K-Akt signaling pathway [66]. In response to these activated signals, HCC may occur growth, invasion and metastasis. Using SU11274, c-Met inhibitor, to neutralize c-Met phosphorylation, the proliferation and invasion of HCC were inhibited [66]. We thus suggest that activation c-Met phosphorylation by DCP might be fundamental for HCC progression.

DCP stimulates HCC growth through the DCP-Met-JAK1-STAT3 signaling pathway

As described above, binding of DCP with c-Met could lead to activation of multiple tyrosines to trigger various cellular events, including HCC proliferation. Suzuki et al. in their recent studies indicated that activation of the DCP-c-Met-Janus kinase 1-STAT3 (Janus kinasesignal transducers and activators of transcription) kinase cascade might be an important signaling pathway involving in stimulation of HCC growth [66]. When Hep3B and SK-Hep-1 cells were exposed to DCP, the ability of DNA synthesis was significantly stimulated. Further analysis indicated thatDCP binding with c-Met was in Tyr1234/1235 site and therefore caused c-Met autophosphorylation. Luciferase gene reporter analysis indicated that this binding of DCP with c-Met could further induce STAT3 activation and therefore lead to transcription [66]. On the other hand, using STAT3 inhibitor peptide and siRNA against STAT3, the STAT3induced transcription as well as DCP-induced cell proliferation was abrogated [66]. Thus, DCP-Met-JAK1-STAT3 kinase cascade might be a major signaling pathway in stimulation of HCC growth.

DCP induces matrix metalloproteinase activity and HCC invasion through ERK1/2 MAPK signaling pathway

Invasion and metastasis, especially intrahepatic metastasis, are the main factors that are responsible for poor prognosis of HCC. High levels of DCP have been found to be associated with invasion and metastasis of hepatocellular carcinoma, portal vein tumor invasion, hepatic vein tumor thrombosis [67]. In our study, DCP was found to possess the activity of stimulation HCC release matrix metalloproteinase (MMPs) [64]. When HLE and SK-Hep cells were exposed to DCP, the ability of migration and invasion of these cells through the Matrigel were significantly increased, indicating the degradation of MMPs. The gelatin zymography and Western blot analyzed the supernatants of the cultured HCC cells, showing that DCP degraded and stimulated HCC release of MMPs, mainly MMP-2 and MMP-9. The levels of released MMPs were well correlated with the increases of phospho-c-Met expression and autophosphorylation of EGFR. These results suggested that DCP might play important roles in stimulation of HCC growth, invasion and metastasis. Activation of the ERK1/2 MAPK kinase cascade might be the response to DCP stimulation. It is well known that the mitogenactivated protein kinases (MAPKs) are a widely conserved family of serine/threonine protein kinases involving in many cellular programs such as proliferation, motility, differentiation and invasion. The p44/42 ERK1/2 MAPK kinase cascade can be activated in response to a diverse range of extracellular stimuli including mitogens, growth factors, and cytokines. Our studies in HLE and SK-Hep cells revealed that DCP could activate p44/42 ERK1/2 phosphorylation as early as $5 \mathrm{~min}$ and reached its maximum expression at $120 \mathrm{~min}$ [64]. We thus suggested that ERK1/2 might be a downstream component of an evolutionarily conserved signaling module that is activated by the Raf serine/threonine kinases. Raf activates the MAPK/ERK kinase (MEK)1/2 dual-specificity protein kinases, which might activate ERK1/2. Based on these suggestions, we measured the expressions of phosphorylation-MEK1/2 (Ser217/221) and phosphorylationc-Raf following DCP stimulation. Additionally, the Raf-MEK-ERK pathway is a key downstream effector of Ras small GTPase, while Ras is a key downstream effector of EGFR. Activation of the Raf-MEK-MAPK signaling pathway may depend on phosphorylation of EGFR. Accordingly, the internalization of phosphorylation-EGFR might occur during the short time of DCP stimulation. To block ERK1/2 MAPK signaling pathway with ERK1/2 inhibitor PD98059, the DCP-induced MMP-2 and MMP-9 activity was abolished and the levels of phosphorylation-c-Met and EGFR were significantly decreased [64]. We 
thus suggest that activation of EGFR-Ras-Raf-MEK-ERK kinase cascades might involve in the processes of DCP stimulation for HCC invasion and metastasis.

\section{The roles of DCP in angiogenesis of HCC}

HCC is mainly a hypervascular tumor and the progression of invasion and metastasis is highly correlated with angiogenesis. Angiogenesis is an important event to support continuous growth of HCC tissues and worsening tumor behavior. Angiogenesis actually starts with cancerous cells releasing angiogenic factors secreted from tumor cells, vascular endothelial cells, and infiltrating cells. These angiogenic factors might further stimulate the proliferation and migration of vascular endothelial cells, leading to the formation of solid endothelial cell sprouts in stromal space [68]. Currently, dozens of molecules have been identified in HCC angiogenesis, such as EGFR, VEGF, FGF, TGF- $\alpha$, bFGF and MMPs etc. Recent studies suggested that DCP might be a novel angiogenic factor to function through affecting the production and release of angiogenesis-related molecules in HCC cells or vascular endothelial cells $[69,70]$.

\section{DCP increases microvascular density (MVD) in HCC tissues}

In a comparative study by Matsubara et al. showed that high levels of plasma DCP were well correlated with the intratumoral microvascular density (MVD) and tumor size in the HCC tissues [71]. Immunohistochemical analysis indicated that the levels of DCP and phospho-KDR were significantly higher in the hypervascular HCC tissues than in the hypovascular HCC tissues [71]. Our study revealed that DCP was efficient to stimulate the proliferation and migration of human vascular endothelial cells (HUVECs) through the reconstituted extracellular matrix [72]. When HUVECs were exposed to DCP, many angiogenic factors, such as EGFR, VEGF and MMPs, were significantly increased and that the tube formation of HUVEC on the 3-D Matrigel was activated. We examined the expressions of angiogenic factors in the HCC xenografts bearing in nude mice and found that in the DCP injected mice, the size of HCC xenografts was obviously increased as compared with the control mice. Immunohistochemical analysis showed the high levels of VEGF, TGF- $\alpha$, and bFGF as well as high MVD in these HCC xenografts [71]. We therefore considered DCP as a novel angiogenic factor for stimulation of HCC growth.

\section{DCP-KDR-PLC- $\gamma-M A P K$ might be a signaling pathway in angiogenesis}

As described above, DCP could increase the release of angiogenic factors from both HCC cells and vascular endothelial cells. Among these molecules, VEGF might play a major role as it robustly stimulates proliferation, migration, and morphogenesis of vascular endothelial cells. By using immunoprecipitation technique, Fujikawa et al. found that DCP's actions might result from its activity of directly binding with KDR, the cell surface kinase insert domain receptor in vascular endothelial cells. KDR may also play its function as vascular endothelial growth factor receptor-2 [8,73]. Based on these discoveries, we consider that DCP might play the roles very similar to VEGF. DCP could induce autophosphorylation of KDR, its downstream effector phospholipase C- $\gamma$ (PLC- $\gamma$ ), mitogen-activated protein kinase (MAPK), and subsequently increase DNA synthesis and cell migration. Using KDR short interfering RNA, KDR kinase inhibitor, or MAPK inhibitor, the DCP-induced cell proliferation and migration were blocked [8]. It is thus reasonable to suggest that DCP might stimulate HCC angiogenesis through activation of the DCP-KDR-PLC- $\gamma$-MAPK signaling pathway. These findings provide us a reason to understand the mechanism of DCP as a paracrine factor in integrate HCC with vascular endothelial cells in the progression of HCC.

Other possible kinase cascades related to angiogenesis

DCP might stimulate angiogenesis in HCC through activation of many other kinase cascades. We found that DCP could induce angiogenesis through activation of MMPs, 


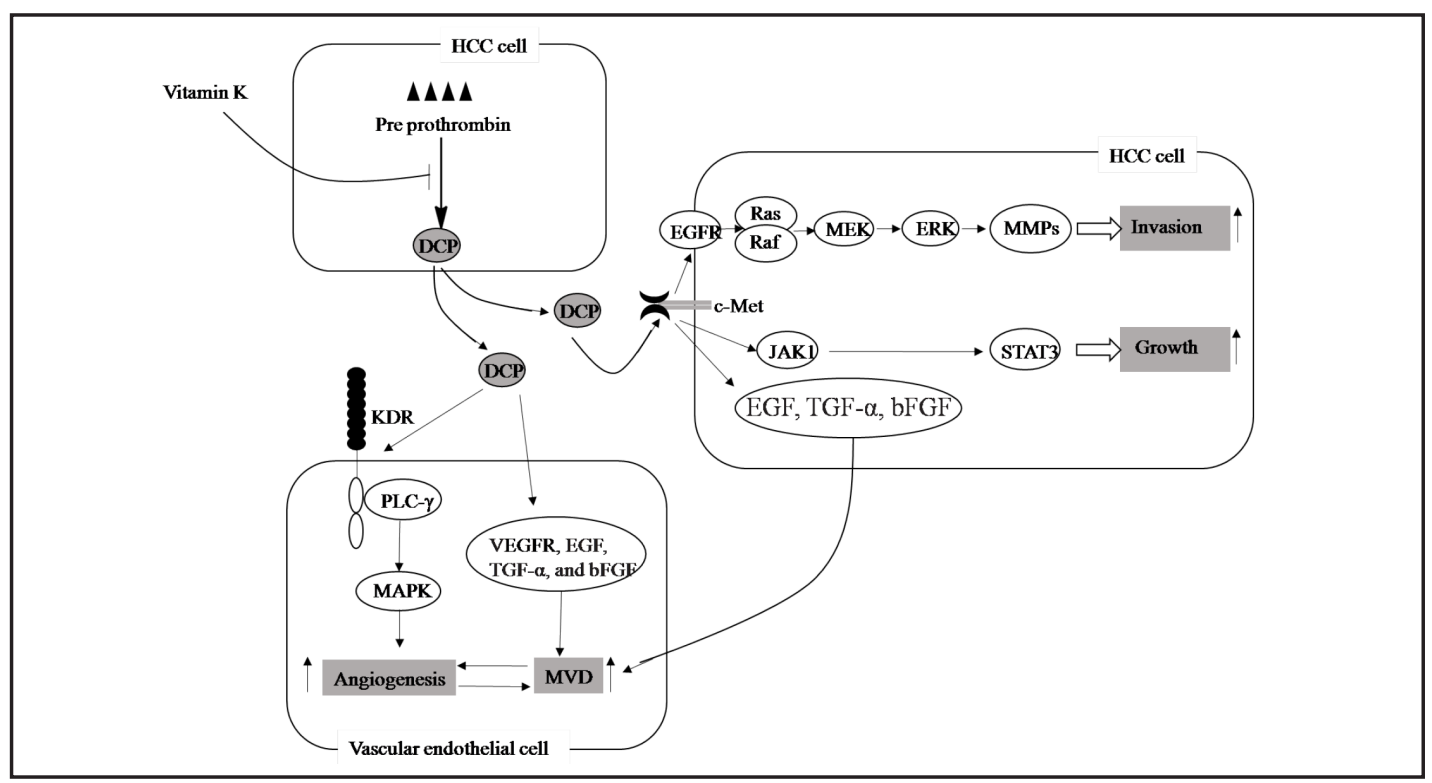

Fig. 3. The summary of the roles and mechanisms of DCP in HCC growth, invasion and angiogenesis. Vitamin K deficiency and decrease of $\gamma$-glutamyl carboxylase in HCC cause DCP production. The autocrine secretion of DCP activates c-Met phosphorylation and affects self-proliferation of HCC through the c-MetJAK-STAT3 pathway. DCP stimulates HCC invasion through activation of the ERK1/2 MAPK pathway. The paracrine secretion of DCP stimulates proliferation and migration of vascular endothelial cells via release of VEGF, TGF- $\alpha$, and bFGF etc and activation of the KDR-PLC- $\gamma$-MAPK pathway.

including MMP-2 and MMP-9 in both HCC cells and vascular endothelial cells $[63,71]$. We suggest that the activated vascular endothelial cells by DCP might stimulate these MMPs to break down extracellular matrix (ECM) toward the source of angiogenic stimulus for proliferation and migration of HCC. The activated MMPs in vascular endothelial cells might release the sequestered angiogenesis factors, such as EGFR, VEGF, FGF, TGF- $\alpha$ and bFGF, to further stimulate capillary tube formation. It is well known that the activated MMP-2 has a great affinity for fibronectin, laminins, elastin, and collagens, degrading them and promoting endothelial cell invasion into the surrounding interstitial matrix. MMP-2 may also activate such factors as mitogenic factors including EGFR, VEGF, FGF-2 and TGF-b during the degradation of ECM. At the same time, angiogenic factors released from HCC cells might integrate with vascular endothelial cells to further stimulate angiogenesis. Therefore, activation or release of MMPs from HCC cells and vascular endothelial cells after DCP stimulation might be a critical step to trigger other kinase cascades related to angiogenesis. Further study should be conducted to elucidate the mechanisms of these kinase cascades in HCC angiogenesis.

The roles and mechanisms of DCP in HCC growth, invasion and angiogenesis are summarized in Fig. 3.

\section{Conclusion and future perspectives}

Early diagnosis and proper therapeutics are always the most important factors to improve survival rate for cancer patients in current medical treatment. Although some multi-targeted kinase inhibitors like sorafenib have been used for treatment of HCC, they provided limited benefit with lower response rates for most of patients [74-76]. DCP has been determined as a very specific marker for diagnosis of relatively early stage of HCC. DCP has now been found to play important roles in stimulation of HCC growth and angiogenesis. Although many issues have still been poorly known, some signaling pathways behind DCP action have been revealed. These findings have provided some crucial clues to investigate DCP 
inhibitors for HCC treatment. If these signaling pathways can be blocked by DCP inhibitor, the progression of HCC might be inhibited. However, constructing DCP inhibitors will not be simple because its three-dimensional conformation has not been fully understood up to now. Moreover, many other kinase cascades related to DCP have still been unknown. Studies on these kinase cascades and constructing DCP inhibitors should be further conducted.

\section{Disclosure Statement}

We confirm that there is no potential conflict of interest or financial dependence regarding this paper.

\section{Acknowledgements}

This work was supported by the fund from Natural Science Foundation of China (81173090). We behold genuine thankfulness to Dr Wei Tang at Graduate School of Medicine, University of Tokyo for his help in fund application.

\section{References}

$>1$ Naraki T, Kohno N, Saito H, Fujimoto Y, Ohhira M, Morita T, Kohgo Y: gamma-Carboxyglutamic acid content of hepatocellular carcinoma-associated des-gamma-carboxy prothrombin. Biochim Biophys Acta 2002;1586:287-298.

- Inagaki Y, Tang W, Makuuchi M, Hasegawa K, Sugawara Y, Kokudo N: Clinical and molecular insights into the hepatocellular carcinoma tumour marker des- $\gamma$-carboxyprothrombin. Liver Int 2011;31:22-35.

- Liebman HA, Furie BC, Tong MJ, Blanchard RA, Lo KJ, Lee SD, Coleman MS, Furie B: Des-gamma-carboxy (abnormal) prothrombin as a serum marker of primary hepatocellular carcinoma. N Engl J Med 1984;310:1427-1431. Yuen MF, Lai CL. Serological markers of liver cancer. Best Pract Res Clin Gastroenterol 2005;19:91-99. Shimada M, Yamashita Y, Hamatsu T, Hasegawa H, Utsunomiya T, Aishima S, Sugimachi K: The role of des-gamma-carboxy prothrombin levels in hepatocellular carcinoma and liver tissues. Cancer Lett 2000;159:87-94.

6 Zhou L, Liu J, Luo F: Serum tumor markers for detection of hepatocellular carcinoma. World J Gastroenterol 2006;12:1175-1181.

7 Gotoh M, Nakatani T, Masuda T, Mizuguchi Y, Sakamoto M, Tsuchiya R, Kato H, Furuta K: Prediction of invasive activities in hepatocellular carcinomas with special reference to alpha-fetoprotein and desgamma-carboxyprothrombin. Jpn J Clin Oncol 2003;33:522-526.

8 Fujikawa T, Shiraha H, Ueda N, Takaoka N, Nakanishi Y, Matsuo N, Tanaka A, Sakaguchi K, Shiraton Y: Desgamma-carboxyl prothrombin-promoted vascular endothelial cell proliferation and migration. J Biol Chem 2007;282:8741-8748.

-9 Suttie JW: Vitamin K-dependent carboxylase. Annu Rev Biochem 1985;54:459-477.

10 Furie B, Furie BC: Molecular basis of vitamin K-dependent gamma-carboxylation. Blood 1990;75:17531762.

11 Fujikawa T, Shiraha H, Yamamoto K: Significance of des-gamma-carboxy prothrombin production in hepatocellular carcinoma. Acta Med Okayama 2009;63:299-304.

12 Uehara S, Gotoh K, Handa H, Honjo K, Hirayama A: Process of carboxylation of glutamic acid residues in the gla domain of human des-gamma-carboxyprothrombin. Clin Chim Acta 1999;289:33-44.

13 Wajih N, Sane DC, Hutson SM, Wallin R: The inhibitory effect of calumenin on the vitamin K-dependent gamma-carboxylation system. Characterization of the system in normal and warfarin-resistant rats. J Biol Chem 2004;279:25276-25383.

14 Li ZQ, He FY, Stehle CJ, Wang Z, Kar S, Finn FM, Carr Bi: Vitamin K uptake in hepatocytes and hepatoma cells. Life Sci 2002;70:2085-2100.

15 Saito M, Seo Y, Yano Y, Miki A, Yoshida M, Azuma T: A high value of serum des- $\gamma$-carboxy prothrombin before hepatocellular carcinoma treatment can be associated with long-term liver dysfunction after treatment. J Gastroenterol 2012;47:1134-1142. 
Zhang et al.: DCP is a Potential Autologous Growth Factor for HCC

16 Liebman HA: Isolation and characterization of a hepatoma-associated abnormal (des-gamma-carboxy) prothrombin. Cancer Res 1989;49:6493-6497.

17 Liska DJ, Suttie JW: Location of gamma-carboxyglutamyl residues in partially carboxylated prothrombin preparations. Biochemistry 1988;27:8636-41.

18 Sorciano-Garcia M, Padmanabhan K, de Vos AM, Tullunsky A: The Ca2+ ion and membrane binding structure of the Gla domain of Ca-prothrombin fragment 1. Biochemistry 1992;31:2554-2566.

19 Ratcliffe JV, Furie B, Furie BC: The importance of specific $\gamma$-carboxyglutamic acid residues in prothrombin. J Biol Chem 1993;268:24339-24345.

20 Uehara S, Gotoh K, Handa H, Tomita H, Senshuu M: Distribution of the heterogeneity of des-gammacarboxyprothrombin in patients with hepatocellular carcinoma. J Gastroenterol Hepatol 2005;20:15451552.

21 Koike Y, Shiratori Y, Sato S, Obi S, Teratani T, Imamura M, Yoshida H, Shiina S, Omata M: Des-gammacarboxyprothrombin as a useful predisposing factor for the development of portal venous invasion in patients with hepatocellular carcinoma. Cancer 2001;91:561-569.

22 Brown MA, Stenberg LM, Persson U, Stenflo J: Identification and purification of vitamin K-dependent proteins and peptides with monoclonal antibodies specific for gamma -carboxyglutamyl (Gla) residues. J Biol Chem 2000;275:19795-19802.

23 Sekiya C, Kohda H, Hasebe C, Namiki M, Watanabe K, Naraki T: Characteristics of the PIVKA-II found in hepatocellular carcinoma: Investigation using monoclonal antibodies MU-3 and 19B7. Int Hepatol Commun 1994;2:277-284.

-24 Ohhira M, Ohtake T, Saito H, Ikuta K, Tanaka K, Tanabe H, Kawashima T, Fujimoto Y, Naraki T, Ono M, Kohgo Y: Increase of serum des-gamma-carboxy prothrombin in alcoholic liver disease without hepatocellular carcinoma. Alcohol Clin Exp Res 1999;23:67S-70S.

25 Murata K, Suzuki H, Okano H, Oyamada T, Yasuda Y, Sakamoto A: Hypoxia-induced des-gamma-carboxy prothrombin production in hepatocellular carcinoma. Int J Oncol 2010;36:161-170.

-26 Suzuki H, Murata K, Gotoh T, Kusano M, Okano H, Oyamada T, Yasuda Y, Imamura M, Kudo M, Mizokami M, Sakamoto A: Phenotype-dependent production of des- $\gamma$-carboxy prothrombin in hepatocellular carcinoma. J Gastroenterol 2011;46:1219-1229.

27 Miyahara K, Nouso K, Morimoto Y, Tomoda T, Kobayashi S, Takeuchi Y, Hagihara H, Kuwaki K, Ohnishi H, Ikeda F, Miyake Y, Nakamura S, Shiraha H, Takaki A, Yamamoto K; Okayama Liver Cancer Group: Evaluation of the effect of sorafenib using serum NX-des- $\gamma$-carboxyprothrombin in patients with hepatocellular carcinoma. Hepatol Res 2013;43:1064-1070.

28 Zhang Q, Bai X, Chen W, Ma T, Hu Q Liang C, Xie S, Chen C, Hu L, Xu S, Liang T: Wnt/ $\beta$-catenin signaling enhances hypoxia-induced epithelial-mesenchymal transition in hepatocellular carcinoma via crosstalk with hif-1 $\alpha$ signaling. Carcinogenesis 2013;34:962-973.

29 Murata K, Suzuki H, Okano H, Oyamada T, Yasuda Y, Sakamoto A: Cytoskeletal changes during epithelialto-fibroblastoid conversion as a crucial mechanism of des-gamma-carboxy prothrombin production in hepatocellular carcinoma. Int J Oncol 2009;35:1005-1014.

-30 Murata K, Sakamoto A: Impairment of clathrin-mediated endocytosis via cytoskeletal change by epithelial to fibroblastoid conversion in HepG2 cells: a possible mechanism of des-gamma-carboxy prothrombin production in hepatocellular carcinoma. Int J Oncol 2008;33:1149-1155.

31 Bertino G, Ardiri AM, Calvagno GS, Bertino N, Boemi PM: Prognostic and diagnostic value of des- $\gamma$-carboxy prothrombin in liver cancer. Drug News Perspect 2010;23:498-508.

32 Goodstadt L, Ponting CP: Vitamin K epoxide reductase: homology, active site, and catalytic mechanism. Trends Biochem Sci 2004;29:289-292.

33 Yamagata H, Nakanishi T, Furukawa M, Okuda H, Obata H: Levels of vitamin K, immunoreactive prothrombin, des-gamma-carboxy prothrombin and gamma-glutamyl carboxylase activity in hepatocellular carcinoma tissue. J Gastroenterol Hepatol 1995;10:8-13.

34 Shah DV, Engelke JA, Suttie JW: Abnormal prothrombin in the plasma of rats carrying hepatic tumors. Blood 1987;69:850-854.

35 Shah DV, Zhang P, Engelke JA, Bach AU, Suttie JW: Vitamin K-dependent carboxylase activity, prothrombin mRNA, and prothrombin production in two cultured rat hepatoma cell lines. Thromb Res 1993;70:365373.

-36 Ueda N, Shiraha H, Fujikawa T, Takaoka N, Nakanishi Y, Suzuki M, Matsuo N, Tanaka S, Nishina S, Uemura M, Takaki A, Shiratori Y, Yamamoto K: Exon 2 deletion splice variant of gamma-glutamyl carboxylase causes des-gamma-carboxy prothrombin production in hepatocellular carcinoma cell lines. Mol Oncol 2008;2:241-249. 
Zhang et al.: DCP is a Potential Autologous Growth Factor for HCC

37 Otsuka M, Kato N, Shao RX, Hoshida Y, Ijichi H, Koike Y, Taniguchi H, Moriyama M, Shiratori Y, Kawabe T, Omata M: Vitamin K2 inhibits the growth and invasiveness of hepatocellular carcinoma cells via protein kinase A activation. Hepatology 2004;40:243-251.

-38 Lawley WJ, Charlton AJ, Hughson EJ, Grundy HH, Brown PM, Jones A: Development of a cell culture/ELISA assay to detect anticoagulant rodenticides and its application to analysis of rodenticide treated grain. J Agric Food Chem 2006;54:1588-1593.

-39 Miyakawa T, Kajiwara Y, Shirahata A, Okamoto K, Itoh H, Ohsato K: Vitamin K contents in liver tissue of hepatocellular carcinoma patients. Jpn J Cancer Res 2000;91:68-74.

40 Tanaka T, Taniguchi T, Sannomiya K, Takenaka H, Tomonari T, Okamoto K, Kitamura S, Okahisa T, Tamaki $\mathrm{K}$, Mikasa H, Suzuki S, Takayama T: Novel des- $\gamma$-carboxy prothrombin in serum for the diagnosis of hepatocellular carcinoma. J Gastroenterol Hepatol 2013;28:1348-1355.

41 Bertino G, Ardiri AM, Boemi PM, Ierna D, Interlandi D, Caruso L, Minona E, Trovato MA, Vicari S, Li Destri G, Puleo S: A study about mechanisms of des-gamma-carboxy prothrombin's production in hepatocellular carcinoma. Panminerva Med 2008;50:221-226.

42 Tameda M, Shiraki K, Sugimoto K, Ogura S, Inagaki Y, Yamamoto N, Ikejiri M, Takei Y, Ito M, Nobori T: Des- $\gamma$ carboxy prothrombin ratio measured by P-11 and P-16 antibodies is a novel biomarker for hepatocellular carcinoma. Cancer Sci 2013;104:725-731.

43 Ma M, Qu XJ, Mu GY, Chen MH, Cheng YN, Kokudo N, Tang W, Cui SX: Vitamin K2 inhibits the growth of hepatocellular carcinoma via decrease of des-gamma-carboxy prothrombin. Chemotherapy 2009;55:2835 .

44 Ishizuka M, Kubota K, Shimoda M, Kita J, Kato M, Park KH, Shiraki T: Effect of menatetrenone, a vitamin $\mathrm{k} 2$ analog, on recurrence of hepatocellular carcinoma after surgical resection: a prospective randomized controlled trial. Anticancer Res 2012;12:5415-5420.

45 Carr BI, Wang Z, Wang M, Wei G: Differential effects of vitamin K1 on AFP and DCP levels in patients with unresectable HCC and in HCC cell lines. Dig Dis Sci 2011;56:1876-1883.

46 Ono M, Ohta H, Ohhira M, Sekiya C, Namiki M: Measurement of immunoreactive prothrombin, desgamma-carboxy prothrombin, and vitamin $\mathrm{K}$ in human liver tissues: overproduction of immunoreactive prothrombin in hepatocellular carcinoma. Am J Gastroenterol 1990;85:1149-1154.

47 Yamagata H, Nakanishi T, Furukawa M, Okuda H, Obata H: Levels of vitamin K, immunoreactive prothrombin, des-gamma-carboxy prothrombin and gamma-glutamyl carboxylase activity in hepatocellular carcinoma tissue. J Gastroenterol Hepatol 1995;10:8-13.

48 Bertino G, Neri S, Bruno CM, Ardiri AM, Calvagno GS, Malaquarnera M, Toro A, Malaquarmera M, Clementi S, Bertino N, Di Carlo I: Diagnostic and prognostic value of alpha-fetoprotein, des- $\gamma$-carboxy prothrombin and squamous cell carcinoma antigen immunoglobulin M complexes in hepatocellular carcinoma. Minerva Med 2011;363-371.

49 Bertino G, Ardiri A, Malaguarnera M, Malaguarnera G, Bertino N, Calvagno GS: Hepatocellualar carcinoma serum markers. Semin Oncol 2012;39:410-433.

50 Nakao A, Taniguchi K, Inoue S, Harada A, Nonami T, Watanabe K, Takagi H: Usefulness of simultaneous determination of alpha-fetoprotein and des-gamma-carboxy prothrombin in hepatocellular carcinoma. Semin Surg Oncol 1996;12:160-163.

51 Nomura F, Ishijima M, Horikoshi A, Nakai T, Ohnishi K: Determination of serum des-gammacarboxyprothrombin levels in patients with small-sized hepatocellular carcinoma: comparison of the conventional enzyme immunoassay and two modified methods. Am J Gastroenterol 1996;91:1380-1383.

-52 Sugimoto H, Takeda S, Inoue S, Kaneko T, Watanabe K, Nakao A: Des-gamma-carboxy prothrombin (DCP) ratio, a novel parameter measured by monoclonal antibodies MU-3 and 19B7, as a new prognostic indicator for hepatocellular carcinoma. Liver Int 2003;23:38-44.

53 Nagaoka S, Yatsuhashi H, Hamada H, Yano K, Matsumoto T, Daikoku M, Arisawa K, Ishibashi H, Koga M, Sata M, Yano M: The des-gamma-carboxy prothrombin index is a new prognostic indicator for hepatocellular carcinoma. Cancer 2003;98:2671-2677.

54 Cheng J, Wang W, Zhang Y, Liu X, Li M, Wu Z, Liu Z, Lv Y, Wang B: Prognostic role of pre-treatment serum AFP-L3\% in hepatocellular carcinoma: systematic review and meta-analysis. PLoS One 2014;9:e87011.

55 Hu B, Tian X, Sun J, Meng X: Evaluation of individual and combined applications of serum biomarkers for diagnosis of hepatocellular carcinoma: a meta-analysis. Int J Mol Sci 2013;14:23559-23580.

56 Li C, Zhang Z, Zhang P, Liu J: Diagnostic accuracy of des-gamma-carboxy prothrombin versus $\alpha$-fetoprotein for hepatocellular carcinoma: A systematic review. Hepatol Res 2013; doi: 10.1111/hepr.12201. 


\section{Cellular Physiology Cell Physiol Biochem 2014;34:903-915 and Biochemistry \\ Zhang et al.: DCP is a Potential Autologous Growth Factor for HCC}

57 Weitz IC, Liebman HA: Des-gamma-carboxy (abnormal) prothrombin and hepatocellular carcinoma: a critical review. Hepatology 1993;18:990-997.

-58 Shimada M, Yamashita Y, Hamatsu T, Hasegawa H, Utsunomiya T, Aishima S, Sugimachi K: The role of des-gamma-carboxy prothrombin levels in hepatocellular carcinoma and liver tissues. Cancer Lett 2000;159:87-94.

59 Yamashita Y, Tsuijita E, Takeishi K, Fujiwara M, Kira S, Mori M, Aishima S, Taketomi A, Shirabe K, Ishida T, Maehara Y: Predictors for microinvasion of small hepatocellular carcinoma $\leq 2 \mathrm{~cm}$. Ann Surg Oncol 2012;19:2027-2034.

60 Susehiro R, Sugimachi K, Matsumata T: Protein induced by vitamin K absence or antagonist II as a prognostic marker in hepatocellular carcinoma. Comparison with alpha-fetoprotein. Cancer 1994;73:24642671.

-61 Marrero JA, Su GL, Emick D, Conjeevaram HS, Fontana RJ, Lok AS: Des-gamma carboxyprothrombin can differentiate hepatocellular carcinoma from nonmalignant chronic liver disease in American patients. Hepatology 2003;37:1114-1121.

62 Inagaki Y, Qi F, Gao J, Qu X, Hasegawa K, Sugawara Y, Tang W, Kokudo N: Effect of c-Met inhibitor SU11274 on hepatocellular carcinoma cell growth. Biosci Trends 2011;5:52-56.

63 Gao J, Feng X, Inagaki Y, Song P, Kokudo N, Hasegawa K, Sugawara Y, Tang W: Des- $\gamma$-carboxy prothrombin and c-Met were concurrently and extensively expressed in hepatocellular carcinoma and associated with tumor recurrence. Biosci Trends 2012;6:153-159.

64 Yue P, Gao ZH, Xue X, Cui SX, Zhao CR, Yuan Y, Yin Z, Inagaki Y, Kokudo N, Tang W, Qu XJ: Des- $\gamma$-carboxyl prothrombin induces matrix metalloproteinase activity in hepatocellular carcinoma cells by involving the ERK1/2 MAPK signalling pathway. Eur J Cancer 2011;47:1115-1124.

65 Basilico C, Arnesano A, Galluzzo M, Comoglio PM, Michieli P: A high affinity hepatocyte growth factorbinding site in the immunoglobulin-like region of Met. J Biol Chem 2008;283:21267-21277.

66 Suzuki M, Shiraha H, Fujikawa T, Takaoka N, Ueda N, Nakanishi Y, Koike K, Takaki A, Shiratori Y: Desgamma-carboxy prothrombin is a potential autologous growth factor for hepatocellular carcinoma. J Biol Chem 2005;280:6409-6415.

67 Morimoto Y, Nouso K, Wada N, Takeuchi Y, Kinugasa H, Miyahara K, Yasunaka T, Kuwaki K, Onishi H, Ikeda F, Miyake Y, Nakamura S, Shiraha H, Takaki A, Yamamoto K: Involvement of platelets in extra-hepatic metastasis of hepatocellular carcinoma. Hepatol Res 2014; doi: 10.1111/hepr.12315.

68 Muto J, Shirabe K, Sugimachi K, Maehara Y: A review of angiogenesis in hepatocellular carcinoma. Hepatol Res 2014; doi: 10.1111/hepr.12310.

69 Guo RP, Zhong C, Shi M, Zhang CQ Wei W, Zhang YQ, Li JQ: Clinical value of apoptosis and angiogenesis factors in estimating the prognosis of hepatocellular carcinoma. J Cancer Res Clin Oncol 2006;132:547-555.

70 Gao FJ, Cui SX, Chen MH, Cheng YN, Sun LR, Ward SG, Kokudo N, Tang W, Qu XJ: Des-gamma-carboxy prothrombin increases the expression of angiogenic factors in human hepatocellular carcinoma cells. Life Sci 2008;83:815-820.

71 Matsubara M, Shiraha H, Kataoka J, Iwamuro M, Horiguchi S, Nishina S, Takaoka N, Uemura M, Takaki A, Nakamura S, Kobayashi Y, Nouso K, Yamamoto K: Des- $\gamma$-carboxyl prothrombin is associated with tumor angiogenesis in hepatocellular carcinoma. J Gastroenterol Hepatol 2012;27:1602-1608.

72 Wang SB, Cheng YN, Cui SX, Zhong JL, Ward SG, Sun LR, Chen MH, Kokudo N, Tang W, Qu XJ: Des-gammacarboxy prothrombin stimulates human vascular endothelial cell growth and migration. Clin Exp Metastasis 2009;26:469-477.

73 Yamaguchi R, Yano H, Nakashima Y, Ogasawara S, Higaki K, Akiba J, Hicklin DJ, Kojiro M: Expression and localization of vascular endothelial growth factor receptors in human hepatocellular carcinoma and nonHCC tissues. Oncol Rep 2000; 7:725-729.

74 Bertino G, Di Carlo I, Ardiri A, Calvagno GS, Demma S, Malaguarnera G, Bertino N, Malaguarnera M, Toro A, Malaguarnera M: Systemic therapies in hepatocellular carcinoma: present and future. Future Oncol 2013;10:1533-1548.

75 Zhao D, Zhai B, He C, Tan G, Jiang X, Pan S, Dong X, Wei Z, Ma L, Qiao H, Jiang H, Sun X: Upregulation of HIF- $2 \alpha$ induced by sorafenib contributes to the resistance by activating the TGF- $\alpha /$ EGFR pathway in hepatocellular carcinoma cells. Cell Signal 2014;26:1030-1039.

76 Crissien AM, Frenette C: Current management of hepatocellular carcinoma. Gastroenterol Hepatol (NY) 2014;10:153-161. 